\title{
Association between Intake during Multiple Eating Occasions and Total Daily Intake among Japanese Young Women
}

\author{
Tatsuya Koyama* \\ 58-1 Mase, Hamadate, Aomori 030-8505, Japan
}

*Corresponding Author: Tatsuya Koyama, 58-1 Mase, Hamadate, Aomori 030-8505, Japan, Email: t_koyama@auhw.ac.jp

\begin{abstract}
Young women in Japan have a poor dietary intake, subjecting themto a risk of inadequate micronutrient intake. This study examined the dietary intake of Japanese young womenat multiple eating occasions to identify opportunities for more targeted recommendations and strategies to improve the dietary intake of young women. This study involved 21 female university students. Their dietary intakes were estimated using the 7-day dietary record. Participant-defined eating occasions were classified as breakfast, lunch, dinner, and snack. The mean percent contribution to the total daily intake of shortfall nutrients (calcium, iron, vitamin A, thiamine, riboflavin, and vitamin $C$ ) as well as the density, foods consumed, and percentage of days at each occasion were calculated. Daily breakfast consumption had the lowest prevalence $(91 \%)$, except snack. Breakfast contributed $26 \%$ of the total daily energy intake and almost $30 \%$ of the daily calcium and riboflavin intake. Milk consumption contributed $16 \%$ of thedaily calcium intake and $10 \%$ of the riboflavin intake. The key opportunities identified for Japanese young women were to increase breakfast consumption, given the high nutrient densities of breakfasts consumed.
\end{abstract}

Keywords: Young Women, Food Intake, Nutrient Intake, Eating Occasion, Diet Quality, Meal Patterns, Japanese

\section{INTRODUCTION}

Adequate nutrition in young women is important for ensuring health. Despite the importance of nutrition in this stage of life, lower intakes of fruits, vegetables, and milks and higher confectionary intake can lead poor diet quality [1]. Consequently, young Japanese women had lower micronutrient intake and higher percentage of energy from total fat [1]. Moreover, young women (20-29 years) had the highest prevalence of skipping breakfast among women aged $\geq 20$ years [1]. Examining the dietary intakes at multiple eating occasions, which include the total daily food and nutrient intakes, would identify new opportunities for more targeted recommendations and strategies to improve the diet quality of young women.

Some studies investigated the association between eating occasions and total daily intake. For example, skipping meals are associated with lower micronutrient intake [2]. Moreover, the type of breakfast has been associated with total diet quality in Japanese female college students
[3].Moreover, intake of nutrients and food groups at each occasion were examined in Japanese female college students. Nutrients and food groups were not equally distributed across all eating occasions [4].

People tend to eat specific combinations of foods at meals [5], and understanding the meal patterns at a certain eating occasion could be useful for the development of public health nutrition policies and recommendations. Inherently, examining individual eating occasions in the context of the total diet does not provide a complete perspective on the impact that each eating occasion has on total daily intake, and, subsequently, the potential opportunities to improve overall diet quality. Examining the multiple components of each eating occasion can further identify more specific areas that need to be targeted to improve dietary intake. Therefore, this study aimed to take a holistic approach to investigate how food and nutrient intakes at multiple eating occasions contributed to the total daily intake of Japanese female college students.

Page $\mid 4$ 


\section{Materials AND MethodS}

We conducted a cross-sectional survey in Japan between February and March 2015. The study involved 21 female students who majored in nutrition and dietetics from a university. The study was reviewed and approved by the Ethics Committee of the Aomori University of Health and Welfare (1711). All participants provided a written informed consent.

Seven-day non-consecutive dietary records were obtained from each participant. The participants recorded all foods consumed by them on the survey day. They weighted the ingredients in dishes whenever possible using the digital scale. If participants ate out and weighing was difficult, they recorded the restaurant's name and name of dishes. Nutrient intake was calculated based on the standard tables of food composition in Japan (2015; seventh revised version) [6].

We considered seven cases as seven dietary records per participant and analyzed 147 cases. Nutrients examined in this study were selected based on the priority of the Dietary Reference Intakes for Japanese (2010) [7], and we selected calcium, iron, vitamin A, thiamine, riboflavin, and vitamin $\mathrm{C}$.

As part of the dietary record, participants were asked to classify the eating occasion for each

$$
\begin{array}{ll}
\frac{\text { Calcium }_{\text {breakfast }} / \text { Calcium }_{\text {total }}}{\text { Energy }_{\text {breakfast }} / \text { Energy }_{\text {total }}} & =\frac{\% \text { of daily Calcium }}{\% \text { of daily Energy }} \\
\frac{\text { Calcium }_{\text {breakfast }} / \text { Calcium }_{\text {total }}}{\text { Energy }_{\text {breakfast }} / \text { Energy }_{\text {total }}} & =\frac{\text { Calcium }_{\text {breakfast }} / \text { Energy }_{\text {breakfast }}}{\text { Calcium }_{\text {total }} / \text { Energy }_{\text {total }}}
\end{array}
$$

The comparison between the nutrient density index of a single eating occasion and the daily intake provides a context beyond the first approach, where nutrient densities are reported as nutrient/energy (kcal). An index of 1 occurs when the nutrient density of a given eating occasion is equal to the nutrient density of the total daily intake among consumers of that eating occasion (Equation 2). It is important to note that given the low quality of the total day, nutrient density indexes above 1 for micronutrients, and nutrient density indexes less than 1 for nutrients to limit, do not necessary indicate a lack of need to make improvements.

Foods were categorized into 17 groups (cereals, potatoes and starches, sugar and sweeteners, pulses, nuts and seeds, vegetables, fruits, food consumed from four pre-defined options: breakfast, lunch, dinner, and snack. The percentage of days when participants record a food at each eating occasion was reported as the percentage of consumers. Participants were restricted to record one eating occasion at a given time.

The per day percent contribution to total daily energy and nutrient intakes were calculated for each occasion. Two approaches were used to calculate the nutrient density among consumers at the eating occasion. For micronutrients, the nutrient density was calculated per $1000 \mathrm{kcal}$. For example, the calcium intake (mg) at lunch was divided by the energy intake (kcal) at lunch and then multiplied by 1000 . Given the different units for each nutrient, the second approach created a nutrient density index to facilitate the examination of all nutrients simultaneously within each eating occasion [8]. For a given eating occasion, the percentage of total daily nutrient intake was divided by the percentage of the total daily energy intake to give a nutrient density relative to the total daily intake (Equation 1). This nutrient daily energy index is obtained by dividing the nutrient density of eating occasion by the nutrient density of the total daily intake among consumers of a particular eating occasion (Equation 2).

mushrooms, algae, fishes and shellfishes, meats, eggs, milks, fats and oils, confectionaries, beverages, and seasonings and spices) according to the standard tables of food composition in Japan (2015; seventh revised version) [6]. The top five sub-major food groups that largely contributed to the total daily energy, calcium, iron, thiamine, riboflavin, and vitamin $\mathrm{C}$ intake were ranked, and the sum of the top five submajor food groups was calculated for each eating occasion to identify opportunities that can increase the total daily intake.

We considered seven cases as seven dietary records per participant and analyzed 147 cases. The analyses were performed using SPSS ver. 24 (IBM Japan Corporation, Tokyo, Japan). We calculated the mean and $95 \%$ confidence 
interval for energy and nutrient intake from eating occasions, nutrient densities, and density indexes.

\section{RESULTS AND DISCUSSION}

Except snack, breakfast consumption had the lowest prevalence $(90.5 \%)$ and slightly contributed to the total daily energy $(25.8 \%)$ (Table1).Breakfast contributed a smaller proportion of thiamine $(24.4 \%)$ and vitamin C $(23.5 \%)$ than energy, but contributed a higher proportion of calcium (33.1\%) and riboflavin (31.9\%). Subsequently, the nutrient density indexes were less than 1 for thiamine and vitamin $\mathrm{C}$, while those for thiamine and vitamin $\mathrm{C}$ were higher than 1.

Almost all participants (96.6\%) consumed lunch, and lunch contributed just above a third $(35.3 \%)$. Relative to its energy contribution, lunch contributed proportional amounts of vitamin A $(35.0 \%)$ and C (35.1\%). The nutrient density indexes for calcium and thiamine at lunch were all below1.
Dinner contributed $35.8 \%$ of the total energy intake. Dinner contributed the highest proportions of daily iron $(37.5 \%)$, thiamine (40.1\%), and vitamin C (37.9\%). The nutrient density indexes for these nutrients were nearly1.

Approximately a quarter of participants (26.5\%) consumed snacks. Snacks contributed the least to the total daily energy and nutrient intake. Nutrient density indexes for calcium and iron were above 1 .

Examining how eating occasions contributed to the top sources of daily nutrients can identify specific foods to target at each eating occasion, but also the top opportunities across all eating occasions to improve total daily intakes. Examining the percent contribution of foods to total daily intake provides a context for recommendations to change the total daily intakes via a single source of nutrient at a given eating occasion.

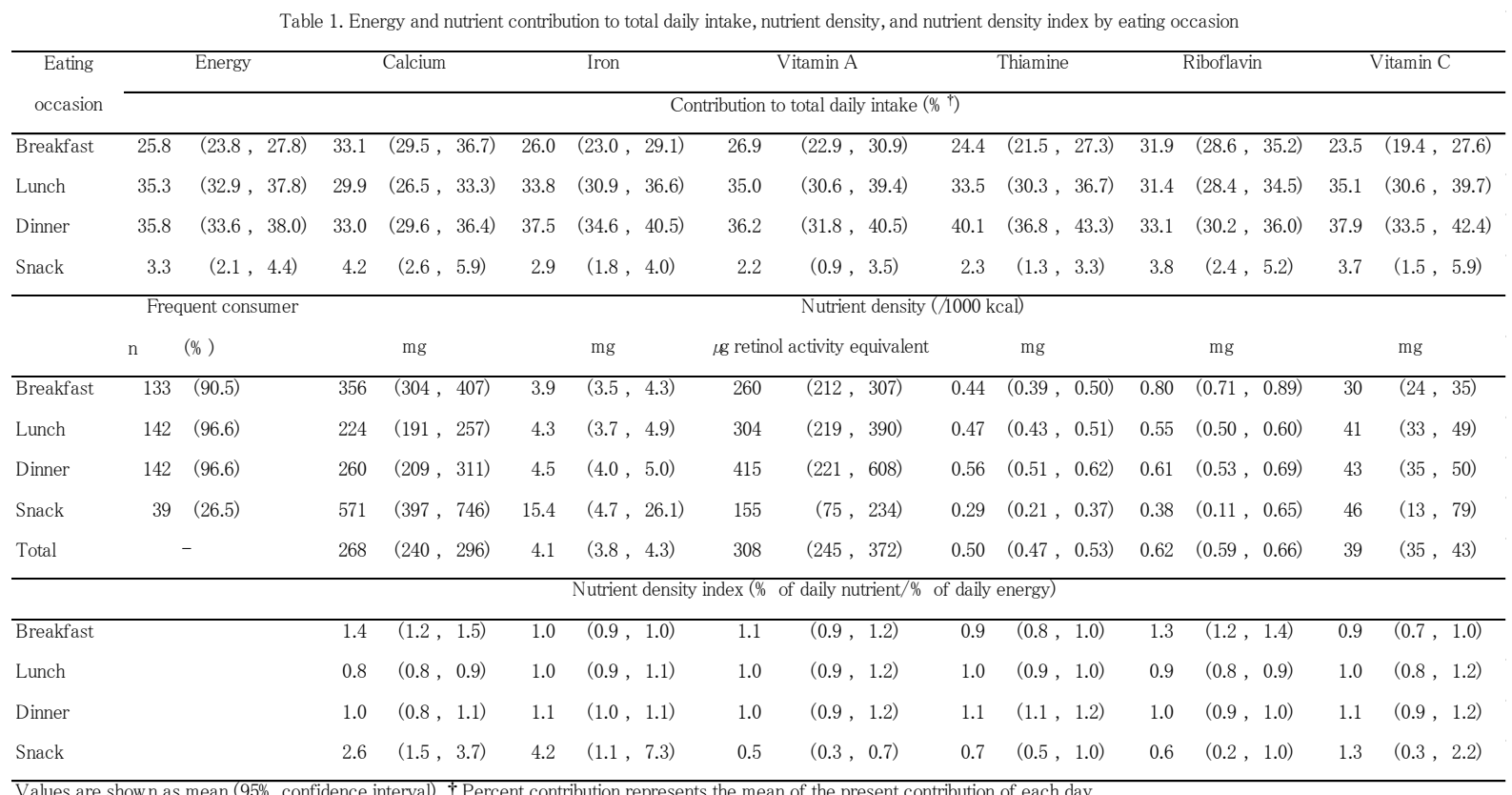

At breakfast, cereals contributed $12.4 \%$ of the daily energy intake (Table 2). Milks were among the top five contributors to the daily energy, calcium, vitamin A, thiamine, and riboflavin intake. Milks consumed at breakfast contributed $3.0 \%$ of energy, $16.4 \%$ of the total calcium, $7.5 \%$ of vitamin A, $3.2 \%$ of energy, and $9.5 \%$ of riboflavin intakes.

Vegetable consumed at lunch contributed $20.2 \%$ of the vitamin A and $26.2 \%$ of the vitamin C intakes. On the other hand, milks were among the top five sources of daily calcium and riboflavin; calcium $(5.5 \%)$ and riboflavin $(3.1 \%)$ had the lowest prevalence among all eating occasions except snack.

At dinner, cereals contributed $16.1 \%$ of the daily energy. Meats were among the top five contributors to daily energy, vitamin A, thiamine, riboflavin, and vitamin C. Meats consumed at dinner contributed $4.8 \%$ of energy, $2.6 \%$ of vitamin A, $13.1 \%$ of thiamine, $7.1 \%$ of riboflavin, and $2.1 \%$ of vitamin $\mathrm{C}$. 
Breakfast contributed less to the total daily energy intake than lunch and dinner, partly due to the higher prevalence of skippers. Among meals, breakfast skippers had the highest prevalence. This finding is consistent with the results of the previous studies [1]. Some studies showed that frequency and reasons of breakfast skipping in Japanese college students depend on the living arrangement [9]. Japanese young women aged 20-29 years had the lowest calciumintake [1]. Peak bone mass reaches the peak level at the age of 20 years [10]. Moreover, calcium intake is associated with bone mineral density in young women [11]. Breakfast with milks promotes calcium intake in young women.

Table 2. Top five sub-major food groups ranked by the contribution of daily energy and nutrient intake

\begin{tabular}{|c|c|c|c|c|c|c|c|c|c|c|c|}
\hline \multirow{3}{*}{$\begin{array}{l}\text { Nutrient } \\
\text { Energy }\end{array}$} & \multirow{3}{*}{$\begin{array}{l}\begin{array}{l}\text { Top five sub-major food } \\
\text { groups }\end{array} \\
\text { Cereals }\end{array}$} & \multirow{2}{*}{\multicolumn{2}{|c|}{$\begin{array}{l}\text { Contributution to total daily } \\
\text { nutrient intake }\left(\%{ }^{\dagger}\right)\end{array}$}} & \multicolumn{8}{|c|}{ Contribution to total daily nutrient intake by eating occasion (\% 1 ) } \\
\hline & & & & \multicolumn{2}{|r|}{ Breakfast } & \multicolumn{2}{|r|}{ Lunch } & \multicolumn{2}{|r|}{ Dinner } & \multicolumn{2}{|r|}{ Snack } \\
\hline & & 46.9 & $(44.8,49.1)$ & 12.4 & $(11.2,13.6)$ & 18.1 & $(16.3,19.9)$ & 16.1 & $(14.7,17.5)$ & 0.3 & $(0.0,0.6)$ \\
\hline & Meats & 10.2 & $(8.8,11.5)$ & 1.1 & $(0.7,1.5)$ & 4.3 & $(3.4,5.2)$ & 4.8 & $(3.9,5.7)$ & 0.0 & $(0.0,0.0)$ \\
\hline & Milks & 6.0 & $(4.9,7.1)$ & 3.0 & $(2.4,3.6)$ & 1.2 & $(0.5,1.9)$ & 1.3 & $(0.8,1.9)$ & 0.4 & $(0.1,0.8)$ \\
\hline & Fishes and shelfishes & 5.1 & $(3.9,6.3)$ & 1.0 & $(0.6,1.4)$ & 1.1 & $(0.6,1.6)$ & 3.0 & $(1.9,4.1)$ & 0.0 & $(0.0,0.0)$ \\
\hline & Seasonings and spices & 4.7 & $(4.0,5.3)$ & 1.1 & $(0.8,1.4)$ & 1.7 & $(1.4,2.1)$ & 1.9 & $(1.4,2.4)$ & 0.0 & $(0.0,0.0)$ \\
\hline & Sum of top sources & & 72.8 & & 18.5 & & 26.4 & & 27.1 & & 0.8 \\
\hline \multirow[t]{6}{*}{$\overline{\text { Calcium }}$} & Milks & 29.6 & $(25.4,33.7)$ & 16.4 & $(13.0,19.8)$ & 5.5 & $(3.2,7.8)$ & 6.0 & $(3.7,8.2)$ & 1.7 & $(0.5,2.9)$ \\
\hline & Vegetables & 22.1 & $(19.3,24.9)$ & 0.8 & $(0.3,1.3)$ & 9.1 & $(7.0,11.2)$ & 8.9 & $(7.3,10.5)$ & 0.1 & $(0.0,0.1)$ \\
\hline & Puluses & 9.2 & $(7.3,11.2)$ & 3.3 & $(2.2,4.3)$ & 1.6 & $(0.8,2.5)$ & 4.3 & $(2.8,5.8)$ & 0.0 & $(0.0,0.0)$ \\
\hline & Cereals & 8.9 & $(7.7,10.2)$ & 2.4 & $(1.9,3.0)$ & 4.0 & $(3.1,4.9)$ & 2.3 & $(1.8,2.7)$ & 0.2 & $(0.0,0.4)$ \\
\hline & Seasonings and spices & 6.6 & $(5.1,8.0)$ & 1.3 & $(0.9,1.7)$ & 2.0 & $(1.5,2.5)$ & 3.2 & $(1.9,4.6)$ & 0.0 & $(0.0,0.0)$ \\
\hline & Sum of top sources & & 76.4 & & 24.2 & & 22.3 & & 24.7 & & 1.9 \\
\hline \multirow[t]{6}{*}{ Iron } & Cereals & 17.1 & $(14.9,19.2)$ & 4.6 & $(3.6,5.7)$ & 7.3 & $(5.6,9.0)$ & 4.8 & $(3.9,5.7)$ & 0.3 & $(0.0,0.7)$ \\
\hline & Vegetables & 15.0 & $(13.5,16.6)$ & 2.8 & $(2.1,3.5)$ & 6.4 & $(5.1,7.6)$ & 5.8 & $(4.9,6.7)$ & 0.1 & $(0.0,0.2)$ \\
\hline & Puluses & 13.1 & $(10.5,15.8)$ & 6.1 & $(4.2,7.9)$ & 2.3 & $(1.1,3.5)$ & 4.7 & $(3.1,6.3)$ & 0.0 & $(0.0,0.0)$ \\
\hline & Eggs & 11.9 & $(9.9,13.9)$ & 4.3 & $(3.1,5.6)$ & 5.0 & $(3.7,6.3)$ & 2.5 & $(1.5,3.5)$ & 0.0 & $(0.0,0.1)$ \\
\hline & Seasonings and spices & 11.5 & $(9.8,13.3)$ & 2.4 & $(1.8,3.1)$ & 3.7 & $(3.0,4.5)$ & 5.4 & $(3.8,6.9)$ & 0.0 & $(0.0,0.0)$ \\
\hline & Sum of top sources & & 68.7 & & 20.3 & & 24.8 & & 23.2 & & 0.4 \\
\hline \multirow[t]{6}{*}{$\overline{\text { Vitamin A }}$} & Vegetables & 51.3 & $(46.4,56.3)$ & 8.9 & $(6.1,11.6)$ & 20.2 & $(16.1,24.3)$ & 21.8 & $(18.1,25.5)$ & 0.5 & $(-0.5,1.5)$ \\
\hline & Eggs & 17.1 & $(13.8,20.4)$ & 6.6 & $(4.4,8.8)$ & 6.9 & $(4.8,8.9)$ & 3.6 & $(2.0,5.3)$ & 0.0 & $(0.0,0.1)$ \\
\hline & Milks & 13.2 & $(10.4,15.9)$ & 7.5 & $(5.4,9.6)$ & 2.7 & $(1.0,4.4)$ & 2.4 & $(1.3,3.5)$ & 0.6 & $(0.1,1.0)$ \\
\hline & Fishes and shelfishes & 4.5 & $(2.5,6.5)$ & 0.7 & $(0.2,1.3)$ & 0.9 & $(0.1,1.7)$ & 2.9 & $(1.2,4.6)$ & 0.0 & $(0.0,0.0)$ \\
\hline & Meats & 3.9 & $(2.1,5.7)$ & 0.1 & $\left(\begin{array}{ll}0.0, & 0.1)\end{array}\right.$ & 1.3 & $(0.6,1.9)$ & 2.6 & $(0.9,4.3)$ & 0.0 & $(0.0,0.0)$ \\
\hline & Sum of top sources & & 90.0 & & 23.8 & & 31.9 & & 33.2 & & 1.1 \\
\hline \multirow[t]{6}{*}{ Thiamine } & Meats & 27.7 & $(24.0,31.4)$ & 3.5 & $(1.7,5.2)$ & 11.1 & $(8.5,13.7)$ & 13.1 & $(10.4,15.9)$ & 0.0 & $(0.0,0.0)$ \\
\hline & Cereals & 19.3 & $(17.0,21.5)$ & 5.3 & $(4.3,6.2)$ & 7.4 & $(6.0,8.9)$ & 6.3 & $(5.0,7.5)$ & 0.3 & $(0.0,0.7)$ \\
\hline & Vegetables & 12.9 & $(11.6,14.2)$ & 2.6 & $(2.0,3.2)$ & 5.2 & $(4.2,6.1)$ & 5.0 & $(4.3,5.7)$ & 0.2 & $(0.0,0.3)$ \\
\hline & Fishes and shelfishes & 8.9 & $(6.7,11.1)$ & 1.8 & $(1.1,2.6)$ & 1.4 & $(0.7,2.1)$ & 5.7 & $(3.6,7.7)$ & 0.0 & $(0.0,0.0)$ \\
\hline & Milks & 6.0 & $(4.7,7.3)$ & 3.2 & $(2.5,4.0)$ & 1.3 & $(0.3,2.4)$ & 1.1 & $(0.6,1.7)$ & 0.3 & $(0.1,0.6)$ \\
\hline & Sum of top sources & & 74.8 & & 16.4 & & 26.4 & & 31.2 & & 0.8 \\
\hline \multirow[t]{6}{*}{ Riboflavin } & Eggs & 17.7 & $(14.8,20.5)$ & 6.2 & $(4.3,8.1)$ & 7.9 & $(5.7,10.0)$ & 3.6 & $(2.2,5.0)$ & 0.0 & $(0.0,0.1)$ \\
\hline & Milks & 16.9 & $(14.1,19.7)$ & 9.5 & $(7.4,11.5)$ & 3.1 & $(1.4,4.8)$ & 3.5 & $(2.1,4.9)$ & 0.8 & $(0.2,1.4)$ \\
\hline & Meats & 13.8 & $(11.8,15.8)$ & 1.4 & $(0.7,2.1)$ & 5.3 & $(4.0,6.6)$ & 7.1 & $(5.6,8.6)$ & 0.0 & $(0.0,0.0)$ \\
\hline & Vegetables & 10.5 & $(9.2,11.8)$ & 1.9 & $(1.3,2.5)$ & 4.5 & $(3.5,5.5)$ & 3.9 & $(3.3,4.6)$ & 0.1 & $(0.0,0.3)$ \\
\hline & Fishes and shelfishes & 9.0 & $(7.0,11.1)$ & 2.1 & $(1.3,2.9)$ & 1.7 & $(0.7,2.6)$ & 5.3 & $(3.4,7.2)$ & 0.0 & $(0.0,0.0)$ \\
\hline & Sum of top sources & & 67.9 & & 21.0 & & 22.5 & & 23.5 & & 0.9 \\
\hline \multirow[t]{6}{*}{$\overline{\text { Vitamin C }}$} & Vegetables & 66.5 & $(62.4,70.6)$ & 13.4 & $(10.0,16.9)$ & 26.2 & $(21.8,30.7)$ & 26.7 & $(22.8,30.6)$ & 0.2 & $(-0.1,0.4)$ \\
\hline & Fruits & 11.9 & $(8.6,15.2)$ & 5.4 & $(3.2,7.5)$ & 2.5 & $(1.2,3.8)$ & 2.7 & $(0.9,4.6)$ & 1.3 & $(-0.1,2.7)$ \\
\hline & Meats & 5.7 & $(4.1,7.3)$ & 0.9 & $(0.4,1.5)$ & 2.7 & $(1.7,3.7)$ & 2.1 & $(1.2,3.0)$ & 0.0 & $\left(\begin{array}{ll}0.0, & 0.0\end{array}\right)$ \\
\hline & Potatoes and starches & 5.1 & $(3.1,7.1)$ & 1.4 & $(0.3,2.5)$ & 0.9 & $(0.3,1.6)$ & 2.4 & $(1.2,3.7)$ & 0.4 & $(-0.4,1.2)$ \\
\hline & Beverages & 4.1 & $(2.1,6.0)$ & 0.4 & $(-0.1,0.8)$ & 0.6 & $(0.3,1.0)$ & 0.7 & $(0.2,1.2)$ & 1.8 & $(0.3,3.4)$ \\
\hline & Sum of top sources & & 93.3 & & 21.5 & & 33.0 & & 34.6 & & 3.7 \\
\hline
\end{tabular}


Vegetables contributed a large proportion of vitamin A and C. Most participants consumed vegetables at lunch and dinner. Japanese people, particularly young adults, consume vegetable much less than the amount recommended by the Health Japan (the second term) [12], which is the national health promotion movement in Japan. Although Health Japan (the second term) had tackled the increasing vegetable consumption in Japan, changes or decline in vegetable consumption have not been reported in the last decade [1]. Japanese people are encouraged to consume more vegetables at breakfast as well as lunch and dinner.

With respect to the daily intakes of specific micronutrients, $15.4 \%$ of women aged 20-29 years were reported to have anemia [13]. The top three sources of iron are plant based. As regards higher iron bioavailability and density, consumption of animal-based protein sources may be an effective means to increase the intake of iron. Moreover, research showed that Japanese young women are more likely to consume meats at lunch or dinner than breakfast [4]. Therefore, promoting the consumption of animal-based sources high in iron at lunch or dinner, with greater vegetable variety, including vegetables that are also high in iron, may help address low iron intakes and improve diet quality.

Cereals include rice, bread, and noodles and were consumed as staple foods by Japanese people. The amount of food consumed from this group was higher than that of other food groups. Accordingly, this food group was among the top five contributors to the daily calcium, iron, and thiamine requirement as well as energy requirement.

\section{CONClusion}

In conclusion, these identified eating occasionspecific opportunities can potentially improve diet quality by increasing intakes of shortfall nutrients among Japanese young women. Increasing the number of young women consuming breakfast with milk and increasing vegetable consumption at breakfast as well as lunch or dinner were the key opportunities identified. Moreover, promoting the consumption of animal-based sources high in iron at lunch or dinner, with greater vegetable variety, including vegetables that are also high in iron, may help address low iron intakes and improve diet quality.

\section{ACKNOWLEDGMENTS}

We express our deepest appreciation to the participants for their cooperation throughout the study. We have no potential conflicts of interest to declare.

\section{REFERENCES}

[1] National Institute of Health and Welfare, The National Survey of Health and Nutrition in Japan 2015, Tokyo, Japan; Daiichi-shuppan, 2017, pp.52-93.

[2] Shiraki M., Iwasaki N., Effect of a habit of skipping meals on dietary life of college students, Jpn J Nutr. 44 (5), 257-265 (1986).

[3] Sasaki S., Shimoda T., Katagiri A., Tsuji T., Amano K., Eating frequency of rice vs. bread at breakfast and nutrient and food-group intake among Japanese female college students. J Community Nutr 4 (2), 83-89 (2002).

[4] Harada M., Yoshida M., Kokaze A., Terada T., Ogino A., Karita K., Relationship on the intake of foods and nutrients by time zones in relation to the habit of skipping-breakfast in college women. Journal for the Integrated Study of Dietary Habits 21 (3), 189-198(2010).

[5] Murakami K., Livingstone MBE., Sasaki S., Establishment of a meal coding system for the characterization of meal-based dietary patterns in Japan. J Nutr. 147 (11), 2093-2101 (2017).

[6] Ministry of Education, Culture, Sports, Science and Technology. The standard tables of food composition in Japan 2015 (seventh revised version).

[7] Sasaki S., Dietary reference intakes for Japanese 2010: Basic concepts for application, J Nutr Sci Vitaminol. 59 (Supplement), S44S52 (2013).

[8] Fayet-Moore F., McConnell A., Kim J., Mathias KC., Identifying Eating Occasion-Based Opportunities to Improve the Overall Diets of Australian Adolescents, Nutrients. 9 (6), E608 (2017).

[9] Nagahata T., Nakada M., Hasegawa J., Kanehira N., Nishibori S., The relationship between skipping breakfast and the living arrangements of university students, Jpn J Nutr Diet. 72 (4), 212-219 (2014).

[10] Weaver CM., Gordon CM., Janz KF., Kalkwarf HJ., Lappe JM., Lewis R., O'Karma M., Wallace TC., Zemel BS., The national osteoporosis foundation's position statement on peak bone mass development and lifestyle factors: a systematic review and implementation recommendations, Osteoporos Int. 27 (4), 1281-1386 (2016).

[11] Nakamura K., Ueno K., Nishiwaki T., Okuda Y., Saito T., Tsuchiya Y., Yamamoto M., Nutrition, mild hyperparathyroidism, and bone 
mineral density in young Japanese women. Am J Clin Nutr. 82 (5), 1127-1133 (2005).

[12] Ministry of Health, Welfare, and Labour. A basic direction for comprehensive implementation of national health promotion. http://www.mhlw.go.jp/file/06-Seisakujouhou-
10900000-Kenkoukyoku/0000047330.pd

[13] Hayashi F., Yoshiike N., Yoshita K., Kawahara K., Trends in the prevalence of anaemia in Japanese adult women, 1989-2003. Public Health Nutr. 11 (3), 252-257 (2008).

Citation: Tatsuya Koyama. Association between Intake during Multiple Eating Occasions and Total Daily Intake among Japanese Young Women. ARC Journal of Nutrition and Growth.2018; 4(1): 4-9. DOI: dx.doi.org/ 10.20431/2455-2550.0401002.

Copyright: (C) 2018 Authors. This is an open-access article distributed under the terms of the Creative Commons Attribution License, which permits unrestricted use, distribution, and reproduction in any medium, provided the original author and source are credited. 